\title{
Is Household Wealth Associated With Use of Long-Acting Reversible and Permanent Methods of Contraception? A Multi-Country Analysis
}

\author{
Jorge I Ugaz, ${ }^{a}$ Minki Chatterii, ${ }^{b}$ James N Gribble, ${ }^{c}$ Kathryn Banke ${ }^{b}$
}

\begin{abstract}
In general, across the developing world, wealthier women are more likely than poorer women to use long-acting and permanent methods of contraception instead of short-acting methods. Exceptions are Bangladesh, India, and possibly Haiti.
\end{abstract}

\begin{abstract}
As programs continue to expand access to family planning information, services, and products, it is critical that these efforts be undertaken with an equity lens, ensuring that regardless of socioeconomic status, all women and couples can use the method that meets their needs. This study explores the relationship between household wealth and the use of long-acting and permanent methods (LAPMs) versus short-acting methods of contraception among modern method users, using multivariate analyses based on Demographic Health Survey data from 30 developing countries conducted between 2006 and 2013. Overall, and controlling for relevant individual and household characteristics including age, number of living children, education, and urban/rural residence, we found that wealthier women were more likely than poorer women to use LAPMs instead of short-acting methods: 20 of the 30 countries showed a positive and statistically significant association between wealth and LAPM use. For 10 of those countries, however, LAPM use was significantly higher only for the top (1 or 2) wealthiest quintiles. Eight countries showed no broad pattern of association, while in 2 countries-Bangladesh and India-poorer women were more likely to use LAPMs than wealthier women. The positive association between wealth and LAPM use was found most consistently in the Latin American and the Caribbean countries in our sample. These findings can help program implementers respond better to women's needs for modern contraception, especially in reaching women from lower- and middle-income households.
\end{abstract}

\section{INTRODUCTION}

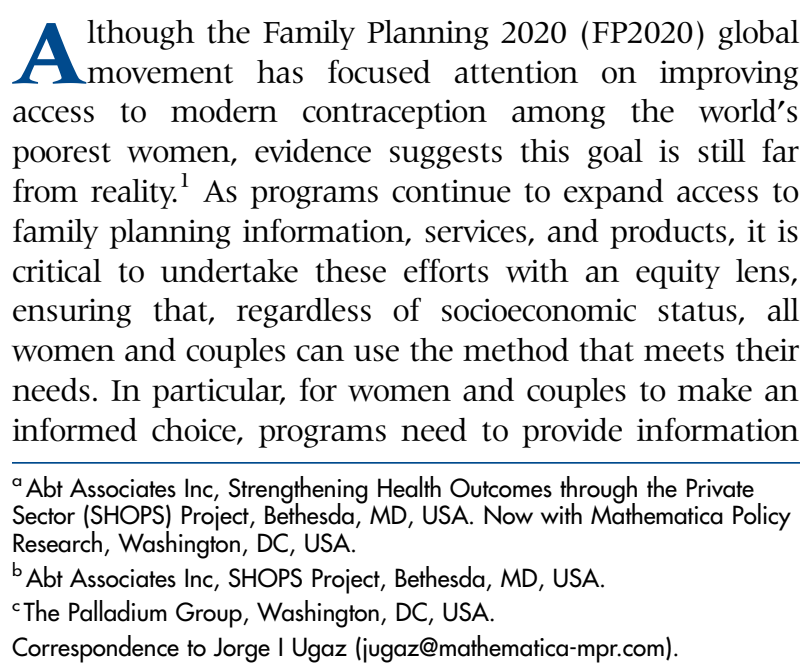

about the benefits of long-acting and permanent methods (LAPMs), as well as access to those methods-either directly or through referrals. LAPMs comprise the long-acting and reversible methods of IUDs and implants as well as the permanent methods of tubal ligation and vasectomy. Benefits of LAPMs include convenience, effectiveness, cost-effectiveness, and potential health benefits, ${ }^{2-4}$ but overall use of LAPMs is still low in developing countries. Regional LAPM contraceptive prevalence rates average $4.2 \%$ and $21.9 \%$ in subSaharan Africa and Latin America, respectively. ${ }^{5}$

Many studies have demonstrated that wealth is positively associated with modern contraceptive use..$^{6-9}$ However, it is unclear whether wealthier women are more likely than poor women to use LAPMs than shortacting methods. To our knowledge, only 3 studies have explored this issue. ${ }^{7,10,11}$ These studies suggest that wealth and LAPM use may be positively associated in developing countries. Creanga et al. $^{7}$ conducted 


\section{Wealth is positively associated with modern \\ contraceptive use, but the association between wealth and use of long- acting over short- acting methods is unclear.}

Most sub-Saharan African countries have low LAPM use. multivariate analysis of Demographic and Health Survey (DHS) data spanning 13 countries in subSaharan Africa and noted that use of long-acting contraceptive methods was more common among women in the wealthiest quintile than women in the poorest wealth quintile. However, by focusing only on the top and bottom wealth quintiles, that analysis left unanswered questions about access for the middle wealth quintiles. Using bivariate analysis, Ross and Agwanda ${ }^{10}$ explored the use of modern methods, in particular injectables, by wealth quintiles using data from DHS and the United Nations Development Programme (UNDP) in 28 countries14 in Eastern and Southern Africa and 14 in West and Central Africa. The study found that women from wealthier households were more likely to be using pills, injectables, condoms, or female sterilization than women from poorer households. Although the results were informative, they do not provide insights into how household wealth is associated with use of one type of method over the others. Similarly, Fotso et al. ${ }^{11}$ analyzed DHS data from Kenya using multivariate regression and found that wealthier women were more likely to use LAPMs than poorer women, a disparity that increased from 2003 through 2008/2009.

Our analysis builds on these prior studies by conducting multivariate regression analysis in 30 countries in 3 regions to explore the relationship between household wealth and the type of contraceptive method used. Multivariate analysis allows us to correct for potential confounders (such as level of education or number of children) that are correlated with wealth and that may affect the choice between LAPMs and short-acting methods. To our knowledge, this is the first study to explore the relationship between wealth and type of method across all wealth quintiles, for many countries and different regions, using multivariate regression techniques to control for confounding factors.

Reasons that poor women may be less likely to use LAPMs could include barriers that programs need to address, such as financial costs, geographic barriers, medical and legal restrictions, ${ }^{12-15}$ provider bias and misinformation, social and cultural barriers, ${ }^{16}$ or simply different preferences. This paper cannot identify the reasons for non-use of LAPMs given data limitations. Rather, the purpose of this article is to determine whether a clear relationship exists between wealth and use of longacting versus short-acting methods of contraception. Substantiating such a relationship allows the family planning community to advocate solutions to close this gap and find ways to remove barriers to LAPM use among poor women through formative and/or intervention research. Making this information available at the country level also helps countries understand whether this is a possible equity issue that needs to be resolved. However, it should be noted that proportions of women who are in need of LAPMs may be different by country because age structures and proportions of women wanting to limit childbearing may differ across countries.

\section{DATA AND METHODS}

Our analysis used data from the DHS, which are household surveys that are nationally representative and internationally comparable, focusing primarily on reproductive health, fertility, and maternal and child health indicators. We used the most recent DHS data from 30 countries across 3 regions: 15 in sub-Saharan Africa; 9 in Asia and the Middle East; and 6 in Latin America and the Caribbean (Table 1). The surveys were conducted between 2006 and 2013.

Our final sample of countries was selected according to the following criteria. First, the most recent DHS was conducted in 2006 or later. Second, of the relevant sample of women of reproductive age (15-49 years) who were not currently pregnant and who had ever been sexually active, at least $10 \%$ reported currently using a modern contraceptive method. Third, the final sample for the country had to have at least 100 users of either LAPMs or shortacting methods among the relevant sample of women.

To assess the prevalence rates of traditional and modern contraception by type of method, we analyzed the sample of women of reproductive age who had ever been sexually active and who reported not being pregnant at the time of the interview. Table 2 displays the proportion of those women who reported using either no method, traditional methods, short-acting methods, or LAPMs for each country. Most countries in sub-Saharan Africa had low use of LAPMs, ranging from $1 \%$ in Cameroon and Nigeria to $7 \%$ in Kenya, Namibia, and Rwanda, and up to $11 \%$ in Malawi. Some countries in Asia and Latin America displayed much higher prevalence rates-from $27 \%$ in Jordan and Nepal to 39\% in Egypt and the Dominican Republic to over $40 \%$ in India and Colombia.

For the multivariate analysis in this paper, we examined the subgroup of women who, in addition to being of reproductive age, sexually active, and not currently pregnant, also reported 
using a modern method of contraception (shortacting methods or LAPMs) at the time of the interview. In some countries in North Africa, the Middle East, and Asia (i.e., Bangladesh, Cambodia, Egypt, Indonesia, Jordan, Nepal, and Pakistan), the questions regarding access to and use of modern contraception were asked only to married women. Table 3 presents descriptive statistics for each study sample in the 30 countries: average age, average number of children alive at time of the interview, education, urban/rural residence, and distribution of the use of modern methods by type (LAPMs vs. short-acting methods). It also displays the numbers of observations of women who have all these requisites per survey that were considered for our analysis.

\section{Variables}

Our outcome of interest was a dichotomous variable that was equal to one if the woman reported using a LAPM and zero if she reported using a short-acting method. Our main independent variable was household wealth, a variable that is included in the DHS datasets as a composite score, based on asset ownership and quality of housing; all surveyed households are ranked by index score and accordingly assigned to 1 of 5 wealth quintiles. ${ }^{17}$ This method of categorizing households based on wealth quintiles has been shown consistent with other wealth rankings, e.g., based on consumption expenditure aggregates, especially when other socioeconomic characteristics are taken into account. ${ }^{18,19}$ In the multivariate analysis, we represented this wealth variable as a vector of 5 dummy variables, with the poorest quintile (quintile 1) serving as the reference group.

Other control variables included:

- Age, in linear and quadratic form

- Number of living children, in linear and quadratic form

- Education, as a vector of dummy variables representing levels of education completed, including none (omitted category), elementary, secondary, and tertiary education

- A vector of dummy variables for employment status and type of occupation of the head of the household (the omitted category was for households in which the head either was unemployed or performed manual or domestic tasks for a living)

- A dummy variable for marital status equal to one for women who were married or living in
TABLE 1. Countries and Survey Years Included in the Analysis

Region/Country Survey Year

sub-Saharan Africa

Burundi

2010

Cameroon

2011

Ethiopia

2011

Kenya

2009

Lesotho

2009

Madagascar

2008

Malawi

2010

Namibia

2006

Nigeria

2013

Rwanda

2010

Senegal

2012

Swaziland

2006

Tanzania

2010

Zambia

2007

Zimbabwe

2010

Asia and the Middle East

Bangladesh

2011

Cambodia

2010

Egypt

2008

India

2006

Indonesia

2007

Jordan

2009

Nepal

2011

Pakistan

2007

Philippines

2008

Latin America and the Caribbean

Bolivia

2008

Colombia

2010

Dominican Republic

2013

Guyana

2009

Haiti

2012

Peru

2008

Source: Demographic and Health Surveys. 
TABLE 2. Use of Contraception Among Women of Reproductive Age, ${ }^{a}$ by Type of Method

\begin{tabular}{|c|c|c|c|c|c|}
\hline Country & None & Traditional & Short-acting & LAPMs & $\mathbf{N}$ \\
\hline \multicolumn{6}{|l|}{ sub-Saharan Africa } \\
\hline Burundi & $78 \%$ & $4 \%$ & $14 \%$ & $4 \%$ & 5,660 \\
\hline Cameroon & $69 \%$ & $10 \%$ & $20 \%$ & $1 \%$ & 11,940 \\
\hline Ethiopia & $71 \%$ & $1 \%$ & $23 \%$ & $4 \%$ & 11,280 \\
\hline Kenya & $58 \%$ & $5 \%$ & $29 \%$ & $7 \%$ & 6,414 \\
\hline Lesotho & $56 \%$ & $1 \%$ & $39 \%$ & $4 \%$ & 6,156 \\
\hline Madagascar & $60 \%$ & $11 \%$ & $26 \%$ & $3 \%$ & 13,872 \\
\hline Malawi & $54 \%$ & $4 \%$ & $31 \%$ & $11 \%$ & 17,701 \\
\hline Namibia & $41 \%$ & $1 \%$ & $50 \%$ & $7 \%$ & 7,679 \\
\hline Nigeria & $80 \%$ & $7 \%$ & $12 \%$ & $1 \%$ & 25,244 \\
\hline Rwanda & $55 \%$ & $6 \%$ & $33 \%$ & $7 \%$ & 8,591 \\
\hline Senegal & $86 \%$ & $1 \%$ & $11 \%$ & $2 \%$ & 10,761 \\
\hline Swaziland & $51 \%$ & $2 \%$ & $42 \%$ & $5 \%$ & 3,837 \\
\hline Tanzania & $62 \%$ & $7 \%$ & $25 \%$ & $6 \%$ & 7,403 \\
\hline Zambia & $61 \%$ & $7 \%$ & $30 \%$ & $2 \%$ & 5,440 \\
\hline Zimbabwe & $44 \%$ & $1 \%$ & $50 \%$ & $4 \%$ & 6,765 \\
\hline \multicolumn{6}{|c|}{ Asia and the Middle East } \\
\hline Bangladesh & $39 \%$ & $9 \%$ & $44 \%$ & $8 \%$ & 16,654 \\
\hline Cambodia & $51 \%$ & $15 \%$ & $28 \%$ & $6 \%$ & 11,912 \\
\hline Egypt & $38 \%$ & $3 \%$ & $21 \%$ & $39 \%$ & 14,950 \\
\hline India & $41 \%$ & $8 \%$ & $9 \%$ & $43 \%$ & 88,075 \\
\hline Indonesia & $39 \%$ & $4 \%$ & $46 \%$ & $11 \%$ & 30,910 \\
\hline Jordan & $36 \%$ & $19 \%$ & $18 \%$ & $27 \%$ & 8,851 \\
\hline Nepal & $48 \%$ & $7 \%$ & $18 \%$ & $27 \%$ & 9,228 \\
\hline Pakistan & $62 \%$ & $10 \%$ & $16 \%$ & $12 \%$ & 12,063 \\
\hline Philippines & $50 \%$ & $17 \%$ & $21 \%$ & $13 \%$ & 8,889 \\
\hline \multicolumn{6}{|c|}{ Latin America and the Caribbean } \\
\hline Bolivia & $44 \%$ & $23 \%$ & $19 \%$ & $13 \%$ & 12,697 \\
\hline Colombia & $28 \%$ & $5 \%$ & $26 \%$ & $41 \%$ & 42,242 \\
\hline Dominican Republic & $31 \%$ & $3 \%$ & $26 \%$ & $39 \%$ & 7,524 \\
\hline Guyana & $57 \%$ & $3 \%$ & $30 \%$ & $11 \%$ & 4,008 \\
\hline Haiti & $69 \%$ & $7 \%$ & $21 \%$ & $3 \%$ & 7,861 \\
\hline Peru & $36 \%$ & $20 \%$ & $30 \%$ & $13 \%$ & 31,261 \\
\hline
\end{tabular}

Abbreviation: LAPMs, long-acting and permanent methods.

a Unit of analysis is women of reproductive (15-49 years old) who have ever been sexually active and who were not currently pregnant.

Source: Demographic and Health Surveys (various years). 
TABLE 3. Descriptive Statistics of Study Sample of Modern Contraceptive Users ${ }^{a}$

\begin{tabular}{|c|c|c|c|c|c|c|c|c|c|c|}
\hline \multirow[b]{2}{*}{ Country } & \multirow[b]{2}{*}{$\begin{array}{l}\text { Average } \\
\text { Age }\end{array}$} & \multirow[b]{2}{*}{$\begin{array}{l}\text { Average No. } \\
\text { of Children }\end{array}$} & \multicolumn{4}{|c|}{ Education } & \multirow[b]{2}{*}{$\begin{array}{l}\text { Living in } \\
\text { Urban Areas }\end{array}$} & \multicolumn{2}{|c|}{$\begin{array}{l}\text { Type of Modern } \\
\text { Method Used }\end{array}$} & \multirow[b]{2}{*}{$\mathbf{N}$} \\
\hline & & & None & Primary & $\begin{array}{l}\text { High } \\
\text { School }\end{array}$ & $\begin{array}{l}\text { College or } \\
\text { Higher }\end{array}$ & & $\begin{array}{l}\text { Short-Acting } \\
\text { Methods }\end{array}$ & LAPMs & \\
\hline \multicolumn{11}{|c|}{ sub-Saharan Africa } \\
\hline Burundi & 30.4 & 3.5 & $43 \%$ & $44 \%$ & $11 \%$ & $2 \%$ & $16 \%$ & $78 \%$ & $22 \%$ & 1,075 \\
\hline Cameroon & 27.3 & 2.0 & $4 \%$ & $26 \%$ & $58 \%$ & $12 \%$ & $73 \%$ & $94 \%$ & $6 \%$ & 2,454 \\
\hline Ethiopia & 29.5 & 3.1 & $51 \%$ & $35 \%$ & $7 \%$ & $7 \%$ & $33 \%$ & $85 \%$ & $15 \%$ & 2,793 \\
\hline Kenya & 31.7 & 3.1 & $3 \%$ & $56 \%$ & $30 \%$ & $10 \%$ & $30 \%$ & $80 \%$ & $20 \%$ & 2,225 \\
\hline Lesotho & 30.2 & 2.0 & $1 \%$ & $43 \%$ & $47 \%$ & $9 \%$ & $40 \%$ & $91 \%$ & $9 \%$ & 2,489 \\
\hline Madagascar & 30.7 & 3.2 & $12 \%$ & $54 \%$ & $32 \%$ & $2 \%$ & $19 \%$ & $90 \%$ & $10 \%$ & 3,889 \\
\hline Malawi & 30.5 & 3.5 & $15 \%$ & $65 \%$ & $18 \%$ & $2 \%$ & $21 \%$ & $73 \%$ & $27 \%$ & 7,449 \\
\hline Namibia & 29.7 & 2.0 & $4 \%$ & $21 \%$ & $66 \%$ & $9 \%$ & $59 \%$ & $87 \%$ & $13 \%$ & 4,321 \\
\hline Nigeria & 29.8 & 2.5 & $9 \%$ & $20 \%$ & $50 \%$ & $22 \%$ & $55 \%$ & $90 \%$ & $10 \%$ & 3,117 \\
\hline Rwanda & 31.5 & 3.3 & $16 \%$ & $72 \%$ & $10 \%$ & $2 \%$ & $14 \%$ & $83 \%$ & $17 \%$ & 3,410 \\
\hline Senegal & 31.9 & 3.5 & $45 \%$ & $34 \%$ & $18 \%$ & $4 \%$ & $69 \%$ & $83 \%$ & $17 \%$ & 1,250 \\
\hline Swaziland & 29.2 & 2.5 & $6 \%$ & $28 \%$ & $55 \%$ & $12 \%$ & $32 \%$ & $89 \%$ & $11 \%$ & 1,837 \\
\hline Tanzania & 30.5 & 3.1 & $14 \%$ & $72 \%$ & $14 \%$ & $1 \%$ & $33 \%$ & $80 \%$ & $20 \%$ & 2,091 \\
\hline Zambia & 29.5 & 3.3 & $10 \%$ & $53 \%$ & $30 \%$ & $7 \%$ & $46 \%$ & $93 \%$ & $7 \%$ & 1,790 \\
\hline Zimbabwe & 30.2 & 2.6 & $2 \%$ & $30 \%$ & $64 \%$ & $5 \%$ & $37 \%$ & $92 \%$ & $8 \%$ & 3,690 \\
\hline \multicolumn{11}{|c|}{ Asia and the Middle East } \\
\hline Bangladesh & 29.8 & 2.4 & $25 \%$ & $30 \%$ & $36 \%$ & $8 \%$ & $27 \%$ & $84 \%$ & $16 \%$ & 8,716 \\
\hline Cambodia & 32.6 & 2.8 & $19 \%$ & $57 \%$ & $23 \%$ & $1 \%$ & $16 \%$ & $83 \%$ & $17 \%$ & 3,993 \\
\hline Egypt & 33.9 & 3.1 & $30 \%$ & $12 \%$ & $46 \%$ & $12 \%$ & $44 \%$ & $35 \%$ & $65 \%$ & 8,524 \\
\hline India & 34.2 & 2.9 & $45 \%$ & $17 \%$ & $32 \%$ & $6 \%$ & $35 \%$ & $17 \%$ & $83 \%$ & 45,224 \\
\hline Indonesia & 33.3 & 2.3 & $5 \%$ & $48 \%$ & $41 \%$ & $7 \%$ & $41 \%$ & $81 \%$ & $19 \%$ & 16,963 \\
\hline Jordan & 34.8 & 4.3 & $2 \%$ & $5 \%$ & $61 \%$ & $32 \%$ & $87 \%$ & $40 \%$ & $60 \%$ & 3,831 \\
\hline Nepal & 34.0 & 2.9 & $54 \%$ & $18 \%$ & $23 \%$ & $5 \%$ & $15 \%$ & $40 \%$ & $60 \%$ & 4,194 \\
\hline Pakistan & 34.4 & 4.2 & $51 \%$ & $18 \%$ & $21 \%$ & $11 \%$ & $41 \%$ & $57 \%$ & $43 \%$ & 3,532 \\
\hline Philippines & 33.7 & 3.1 & $0 \%$ & $21 \%$ & $46 \%$ & $32 \%$ & $53 \%$ & $62 \%$ & $38 \%$ & 3,024 \\
\hline \multicolumn{11}{|c|}{ Latin America and the Caribbean } \\
\hline Bolivia & 32.0 & 2.8 & $4 \%$ & $41 \%$ & $34 \%$ & $21 \%$ & $73 \%$ & $59 \%$ & $41 \%$ & 4,375 \\
\hline Colombia & 32.7 & 2.1 & $2 \%$ & $26 \%$ & $49 \%$ & $24 \%$ & $79 \%$ & $39 \%$ & $61 \%$ & 27,532 \\
\hline $\begin{array}{l}\text { Dominican } \\
\text { Rep. }\end{array}$ & 33.1 & 2.5 & $2 \%$ & $36 \%$ & $36 \%$ & $26 \%$ & $75 \%$ & $40 \%$ & $60 \%$ & 5,026 \\
\hline Guyana & 32.1 & 2.5 & $1 \%$ & $20 \%$ & $70 \%$ & $9 \%$ & $32 \%$ & $73 \%$ & $27 \%$ & 1,541 \\
\hline Haiti & 29.7 & 2.5 & $21 \%$ & $35 \%$ & $38 \%$ & $5 \%$ & $50 \%$ & $86 \%$ & $14 \%$ & 1,874 \\
\hline Peru & 33.1 & 2.5 & $3 \%$ & $26 \%$ & $41 \%$ & $30 \%$ & $75 \%$ & $70 \%$ & $30 \%$ & 13,770 \\
\hline
\end{tabular}


union, and zero otherwise (this variable was used as a control only for those countries where questions regarding use of contraception were asked regardless of marital status, as previously explained)

- Urban/rural residence

We included this vector of controls in order to isolate more precisely the relationship between use of LAPMs versus short-acting methods and wealth, as a proxy for disposable income. Age and education, for example, are variables that are correlated with both wealth and use of either type of method. Controlling for them is equivalent to exploring the nature of the relationship between wealth and use of LAPMs within women of the same age or same level of education. Although some of these controls are highly correlated, in order to improve the precision of our estimates and reduce the potential for omitted variable bias, all of them were included as controls simultaneously.

We hypothesized that most countries would show a positive association between wealth and use of LAPMs (versus short-acting methods). It was expected that this could occur in the form of a positive linear relationship across all wealth quin-

In most countries, wealthier women were more likely to use LAPMs than poorer women. tiles (meaning that women from higher quintiles would always be more likely to use LAPMs than women from lower quintiles) or in the form of a non-linear relationship, i.e., just for the highest quintiles (meaning that women from only the top 1 or 2 highest quintiles would be more likely to use LAPMs, but women from lower quintiles would be equally likely to use LAPMs than women from the lowest quintile). A negative relationship would mean that wealthier women would be less likely to use LAPMs than poorer women.

\section{Analytical Methods}

First, we examined the unadjusted relationship between our outcome of interest (use of LAPMs versus short-acting methods) and our main independent variable (wealth) separately for the 30 countries in our final sample. Second, we ran (adjusted) multivariate logistic regressions for each country, in order to control for specific individual and household characteristics that can confound the relationship between wealth and contraceptive method of choice. These control variables were age, number of living children, educational attainment, employment status and type of occupation of head of household, marital status (when applicable), and urban/rural residence.
The multivariate analysis was performed using logistic regression models to yield coefficient estimates displayed as odds ratios (ORs). These ratios represent the odds of an individual using a LAPM over the odds of using a shortacting method (thus, an odds ratio larger than one implies that the individual is more likely to use a LAPM than a short-acting method). We used the within-country weighting variables specified by each country-specific DHS. Occasionally, a country presented strata with a single sampling unit in our regressions; those strata were treated as certainty sampling units. ${ }^{20}$

\section{RESULTS}

\section{Unadjusted Analysis}

The unadjusted relationship between wealth and use of LAPMs (versus short-acting methods) among modern method users varied across countries (Table 4). The complement of each proportion reported in Table 4 is, by definition, the proportion of women using short-acting methods. In Burundi, for example, among the sampled women in the poorest quintile (quintile 1), 22\% used LAPMs and the remaining $78 \%$ used short-acting methods.

Overall, in 17 of the 30 countries, a greater proportion of women in the wealthiest quintile used LAPMs compared with women in the poorest quintile. Conversely, of course, short-acting methods were used by a greater proportion of poorer women than wealthier women. This positive (and linear) relationship between wealth and use of LAPMs was the dominant pattern in each region, observed in half to two-thirds of the countries sampled: 10 of the 15 African countries, 5 of the 9 Asian/Middle Eastern countries, and 3 of the 6 Latin American/Caribbean countries.

There were many exceptions to this pattern, however. Four countries-Bangladesh, Haiti, India, and Pakistan — exhibited a clearly negative relationship: LAPM use was far more common among poorer women than among wealthier women. For another 4 countries (the Dominican Republic, Ethiopia, Nepal, and Tanzania), the relationship resembled an inverted U-shape, with LAPM use higher in the middle wealth quintiles and lower in both the poorest and the wealthiest quintiles. In Burundi and Senegal, the relationship resembled a U-shape, with LAPM use more likely in both the poorest and the wealthiest quintiles and lower in the middle quintiles; however, no large differences were observed in the proportions across all 
TABLE 4. Proportion of Modern Method Users ${ }^{a}$ Using LAPMs, by Wealth Quintile

\begin{tabular}{|c|c|c|c|c|c|}
\hline \multirow[b]{2}{*}{ Country } & \multicolumn{5}{|c|}{ Wealth Quintile } \\
\hline & Q1 (Poorest) & Q2 & Q3 & Q4 & Q5 (Wealthiest) \\
\hline \multicolumn{6}{|l|}{ sub-Saharan Africa } \\
\hline Burundi & $22 \%$ & $15 \%$ & $20 \%$ & $23 \%$ & $26 \%$ \\
\hline Cameroon & $7 \%$ & $8 \%$ & $8 \%$ & $7 \%$ & $5 \%$ \\
\hline Ethiopia & $16 \%$ & $21 \%$ & $16 \%$ & $16 \%$ & $12 \%$ \\
\hline Kenya & $14 \%$ & $16 \%$ & $21 \%$ & $21 \%$ & $21 \%$ \\
\hline Lesotho & $3 \%$ & $6 \%$ & $7 \%$ & $10 \%$ & $11 \%$ \\
\hline Madagascar & $8 \%$ & $7 \%$ & $7 \%$ & $12 \%$ & $13 \%$ \\
\hline Malawi & $24 \%$ & $23 \%$ & $26 \%$ & $28 \%$ & $32 \%$ \\
\hline Namibia & $5 \%$ & $6 \%$ & $8 \%$ & $13 \%$ & $22 \%$ \\
\hline Nigeria & $6 \%$ & $8 \%$ & $10 \%$ & $9 \%$ & $12 \%$ \\
\hline Rwanda & $12 \%$ & $15 \%$ & $15 \%$ & $18 \%$ & $25 \%$ \\
\hline Senegal & $21 \%$ & $17 \%$ & $14 \%$ & $15 \%$ & $19 \%$ \\
\hline Swaziland & $6 \%$ & $9 \%$ & $10 \%$ & $9 \%$ & $16 \%$ \\
\hline Tanzania & $17 \%$ & $24 \%$ & $20 \%$ & $22 \%$ & $18 \%$ \\
\hline Zambia & $2 \%$ & $5 \%$ & $6 \%$ & $5 \%$ & $13 \%$ \\
\hline Zimbabwe & $6 \%$ & $6 \%$ & $5 \%$ & $7 \%$ & $14 \%$ \\
\hline \multicolumn{6}{|c|}{ Asia and the Middle East } \\
\hline Bangladesh & $21 \%$ & $18 \%$ & $16 \%$ & $13 \%$ & $10 \%$ \\
\hline Cambodia & $14 \%$ & $14 \%$ & $12 \%$ & $17 \%$ & $31 \%$ \\
\hline Egypt & $53 \%$ & $61 \%$ & $64 \%$ & $72 \%$ & $73 \%$ \\
\hline India & $90 \%$ & $89 \%$ & $88 \%$ & $83 \%$ & $71 \%$ \\
\hline Indonesia & $14 \%$ & $17 \%$ & $17 \%$ & $19 \%$ & $29 \%$ \\
\hline Jordan & $56 \%$ & $59 \%$ & $57 \%$ & $60 \%$ & $69 \%$ \\
\hline Nepal & $54 \%$ & $64 \%$ & $66 \%$ & $64 \%$ & $50 \%$ \\
\hline Pakistan & $50 \%$ & $45 \%$ & $47 \%$ & $39 \%$ & $40 \%$ \\
\hline Philippines & $33 \%$ & $38 \%$ & $39 \%$ & $40 \%$ & $41 \%$ \\
\hline \multicolumn{6}{|c|}{ Latin America and the Caribbean } \\
\hline Bolivia & $25 \%$ & $33 \%$ & $39 \%$ & $44 \%$ & $51 \%$ \\
\hline Colombia & $61 \%$ & $62 \%$ & $61 \%$ & $62 \%$ & $59 \%$ \\
\hline Dominican Republic & $52 \%$ & $58 \%$ & $65 \%$ & $62 \%$ & $62 \%$ \\
\hline Guyana & $24 \%$ & $27 \%$ & $29 \%$ & $27 \%$ & $26 \%$ \\
\hline Haiti & $25 \%$ & $18 \%$ & $19 \%$ & $11 \%$ & $10 \%$ \\
\hline Peru & $18 \%$ & $26 \%$ & $27 \%$ & $34 \%$ & $34 \%$ \\
\hline
\end{tabular}

Abbreviations: LAPMs, long-acting and permanent methods; $Q$, quintile.

a Study sample is limited to women of reproductive age who have ever been sexually active, who were not pregnant at the time of the survey, and who reported current use of a modern contraceptive method.

Source: Demographic and Health Surveys (various years). 
quintiles. Finally, in Cameroon, Colombia, and Guyana, there appeared to be no relationship between wealth and type of method used.

\section{Multivariate Analysis}

We used multivariate logistic regression to control for a vector of potentially confounding covariates: age, number of living children, education, employment/occupation, marital status, and urban/rural residence. Table 5 shows the adjusted odds ratios from the multivariate regressions, organized by region.

The 30 countries exhibited 1 of 4 patterns:

In Bangladesh and India (and possibly Haiti), poorer women were more likely than wealthier women to use LAPMs than shortacting methods.
- A consistently positive, statistically significant relationship across all 5 wealth quintiles, such that wealthier women were more likely to use LAPMs and women in the lowest wealth quintiles were more likely to use short-acting methods.

- A positive association between wealth and LAPM use, only when comparing the top 1 or 2 wealthiest quintiles with the poorest quintile, and no significant difference in LAPM use between the lower wealth quintiles and the poorest quintile. That is, women from the lowest 2 or 3 quintiles showed no systematic preference for LAPMs or short-acting methods, and the wealth effect was apparent only in the highest wealth quintiles.

- No significant differences in LAPM use, or a significant difference only when comparing the lower or middle quintiles with the poorest quintile. In these countries, wealth did not appear to be associated positively or negatively with LAPM use.

- A significant negative association between wealth and LAPM use, such that wealthier women were more likely to use short-acting methods and poorer women were more likely to use LAPMs.

These patterns varied by region. In subSaharan Africa, as noted in the unadjusted analysis, 10 of the 15 countries analyzed showed statistically significant and positive relationships overall between wealth and LAPM use. In 3 of these 10 countries (Lesotho, Nigeria, and Zambia), women from almost all upper quintiles were significantly more likely to use LAPMs than women in the poorest quintile. In 6 of the 10 countries (Kenya, Malawi, Namibia, Rwanda, Swaziland, and Zimbabwe), a significant relationship was found only when comparing the top 1 or
2 wealth quintiles with the poorest quintile. Tanzania showed a significant positive association only when comparing the second and fourth quintiles. In the other 5 sampled sub-Saharan African countries (Burundi, Cameroon, Ethiopia, Madagascar, and Senegal), no statistically significant relationship was found when comparing the poorest quintile with any other quintile.

In Asia and the Middle East, a positive and statistically significant relationship between wealth and LAPM use was noted in 5 countries: Cambodia, Egypt, Indonesia, Jordan, and Nepal. In 3 of those countries-Cambodia, Indonesia, and Jordan-the relationship was significant only for women in the wealthiest quintile. In 2 other countries-Bangladesh and India-a significant negative relationship was found: in those countries, as discussed below, poorer women were more likely than wealthier women to use LAPMs rather than short-acting methods. No association was found for Pakistan or the Philippines.

Finally, in Latin America and the Caribbean, 5 of the 6 countries showed positive and statistically significant associations between wealth and LAPM use, mostly across all wealth quintiles. Haiti was the exception-although the association was not statistically significant, the average odds ratio was around 0.54, suggesting that women from the lowest quintile may be more likely than wealthier women to use LAPMs than short-acting methods, as in Bangladesh and India

There was wide variation in the magnitude of the outcome differences. Some countries showed a markedly larger likelihood of LAPM use for women from the wealthiest quintile. Four countriesBolivia, Lesotho, Namibia, and Zambia-had odds ratios greater than 3 when comparing outcomes between the wealthiest quintile and the poorest quintile, showing the strongest (adjusted) association between wealth and LAPM use.

\section{DISCUSSION}

Using recent data from 30 countries in 3 regions, we examined patterns of use of LAPMs and shortacting methods in relation to household wealth. Our analyses showed a general pattern of greater LAPM use by wealthier women: 20 of the 30 countries showed some pattern of positive and statistically significant association between wealth and LAPM use. However, for 10 of those 20 countries, this pattern was limited to a comparison between the wealthiest 1 or 2 quintiles and the poorest quintile; there was no significant difference 
TABLE 5. Adjusted Odds Ratios for Relationship Between Wealth Quintile and Use of LAPMs vs. Short-Acting Methods Among Study Sample of Modern Method Users ${ }^{a}$

\begin{tabular}{|c|c|c|c|c|c|c|}
\hline Country & Q1 (Poorest) & Q2 & Q3 & Q4 & Q5 (Wealthiest) & $\mathbf{N}$ \\
\hline \multicolumn{7}{|l|}{ sub-Saharan Africa } \\
\hline Burundi & 1.00 & 0.59 & 0.81 & 0.98 & 0.99 & 1,075 \\
\hline Cameroon & 1.00 & 2.04 & 2.13 & 2.69 & 2.70 & 2,454 \\
\hline Ethiopia & 1.00 & 1.47 & 1.07 & 1.04 & 0.81 & 2,793 \\
\hline Kenya & 1.00 & 0.96 & 1.21 & 1.35 & $2.61^{* *}$ & 2,225 \\
\hline Lesotho & 1.00 & $2.53^{*}$ & $2.46+$ & $5.24^{* *}$ & $6.59^{* *}$ & 2,489 \\
\hline Madagascar & 1.00 & 0.79 & 0.70 & 1.31 & 1.21 & 3,889 \\
\hline Malawi & 1.00 & 0.99 & 1.21 & $1.30+$ & $1.74^{* *}$ & 7,449 \\
\hline Namibia & 1.00 & 1.02 & 1.25 & $2.37^{* *}$ & $5.08^{* *}$ & 4,318 \\
\hline Nigeria & 1.00 & 1.65 & $2.17^{*}$ & $2.27^{*}$ & $2.28^{*}$ & 3,117 \\
\hline Rwanda & 1.00 & 1.22 & $1.38+$ & $1.57^{*}$ & $2.02^{* *}$ & 3,410 \\
\hline Senegal & 1.00 & 0.74 & $0.48^{*}$ & 0.56 & 0.83 & 1,250 \\
\hline Swaziland & 1.00 & 1.55 & 1.63 & 1.34 & 1.86 & 1,837 \\
\hline Tanzania & 1.00 & $1.62+$ & 1.37 & $1.94^{*}$ & 1.48 & 2,091 \\
\hline Zambia & 1.00 & $3.31^{*}$ & $4.51^{* *}$ & $4.71^{* *}$ & $11.34^{* *}$ & 1,790 \\
\hline Zimbabwe & 1.00 & 1.04 & 0.72 & 1.05 & $1.80+$ & 3,690 \\
\hline \multicolumn{7}{|c|}{ Asia and the Middle East } \\
\hline Bangladesh & 1.00 & $0.80^{*}$ & $0.69^{* *}$ & $0.59^{* *}$ & $0.54^{* *}$ & 8,755 \\
\hline Cambodia & 1.00 & 0.96 & 0.78 & 0.99 & $1.76^{*}$ & 3,993 \\
\hline Egypt & 1.00 & $1.29^{* *}$ & $1.42^{* *}$ & $1.97^{* *}$ & $1.94^{* *}$ & 8,524 \\
\hline India & 1.00 & $0.87^{*}$ & $0.83^{* *}$ & $0.77^{* *}$ & $0.53^{* *}$ & 45,224 \\
\hline Indonesia & 1.00 & 1.15 & 1.05 & 1.04 & $1.41^{*}$ & 16,963 \\
\hline Jordan & 1.00 & 1.09 & 1.04 & 1.12 & $1.58+$ & 3,831 \\
\hline Nepal & 1.00 & $1.74^{* *}$ & $1.97^{* *}$ & $2.33^{* *}$ & $1.84^{* *}$ & 4,194 \\
\hline Pakistan & 1.00 & 0.85 & 1.05 & 0.88 & 1.06 & 3,532 \\
\hline Philippines & 1.00 & 1.18 & 1.05 & 1.08 & 1.20 & 3,024 \\
\hline \multicolumn{7}{|c|}{ Latin America and the Caribbean } \\
\hline Bolivia & 1.00 & $1.80^{* *}$ & $2.23^{* *}$ & $2.72^{* *}$ & $3.19^{* *}$ & 4,375 \\
\hline Colombia & 1.00 & $1.34^{* *}$ & $1.45^{* *}$ & $1.70^{* *}$ & $1.68^{* *}$ & 27,532 \\
\hline Dominican Republic & 1.00 & $1.52^{*}$ & $1.74^{* *}$ & $1.40+$ & $1.84^{* *}$ & 5,026 \\
\hline Guyana & 1.00 & 1.27 & 1.50 & 1.50 & 1.53 & 1,541 \\
\hline Haiti & 1.00 & $0.55+$ & 0.58 & 0.52 & 0.54 & 1,874 \\
\hline Peru & 1.00 & $1.42^{*}$ & $1.72^{* *}$ & $2.65^{* *}$ & $2.23^{* *}$ & 13,770 \\
\hline
\end{tabular}

Abbreviations: LAPMs, long-acting and permanent methods; $Q$, quintile.

a Study sample is limited to women of reproductive age who have ever been sexually active, who were not pregnant at the time of the survey, and who reported current use of a modern contraceptive method.

$+P<.10, * P<.05, * * P<.01$

Source: Demographic and Health Surveys (various years). 
between usage by women from the poorest households and women from middle-income households. These findings suggest that in many countries the income threshold is high-for reasons that remain to be explored.

The remaining 10 countries analyzed demonstrated 2 different patterns. No significant relationship was found between wealth and type of method used in 8 countries: Burundi, Cameroon, Ethiopia, Madagascar, and Senegal; Pakistan and the Philippines; and Haiti. The other pattern was a significant inverse (negative) relationship between wealth and LAPM use in Bangladesh and India: poorer women were more likely to use LAPMs than wealthier women, and wealthier women were more likely to use short-acting methods than poorer women. This inverse pattern may reflect a different policy environment in these countries, where supplyside and demand-side incentives, reinforced by community mobilization, contribute to high uptake

Inequity in access to LAPMs may be an issue in many developing countries. of LAPMs among the poor. In Bangladesh, for example, LAPM service delivery has been prioritized by the government and is backed with a large budget, including funds for client compensation and provider fees. ${ }^{21}$ In India, female sterilization is the leading method of contraception, accounting for two-thirds of all current contraceptive use and about three-quarters of all modern method use $\mathrm{e}^{22}$; it is provided free of charge in the public sector ${ }^{23}$ and has a long history of government promotion as the primary method of family planning. ${ }^{24}$ Although the Indian government ceased to announce national sterilization targets in 1996, there is some evidence

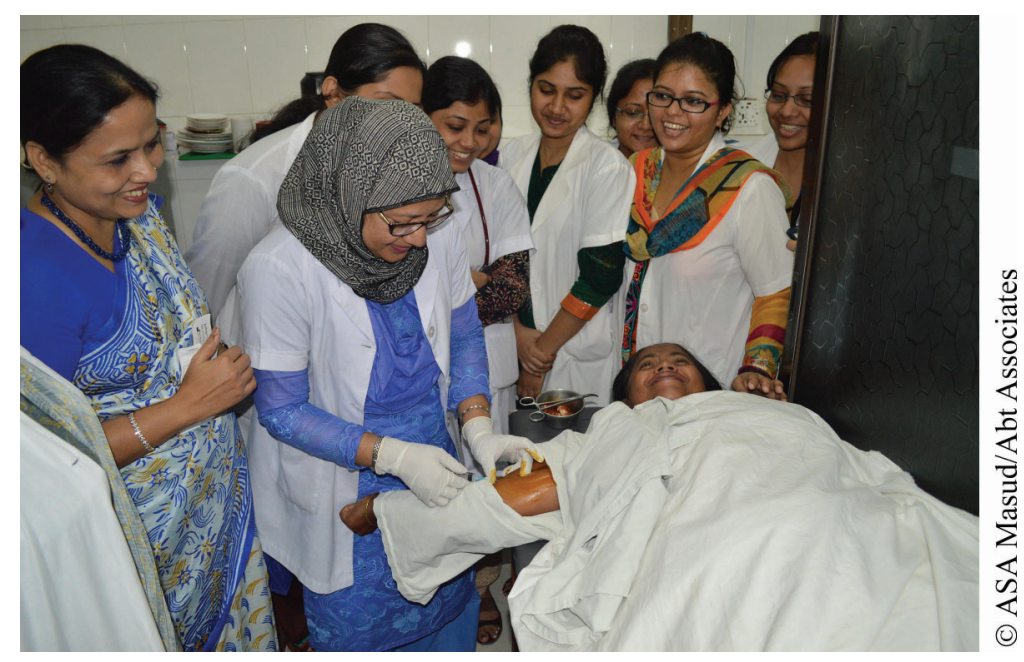

A medical intern in Bangladesh inserts a contraceptive implant in a client's arm under supervision while other interns watch and learn. that targets and reimbursements to cover costs such as travel expenses are still used to encourage female sterilization. ${ }^{25,26}$

While our study did not analyze use of specific LAPMs (e.g., IUDs vs. female sterilization) by wealth, we can assume the patterns are generally similar to regional patterns among all contraceptive users. For example, in Latin America and the Caribbean, out of a modern contraceptive prevalence rate (mCPR) of $58.1 \%$, almost one-third $(31.4 \%)$ is from LAPMs, with a strong presence of female sterilization and, to a lesser extent, IUDs. ${ }^{27}$ In countries from Asia, the Middle East, and North Africa, where the mCPR is $51.7 \%$, LAPMs contribute $14.3 \%$ to that mCPR, with $8 \%$ of women using IUDs and approximately 5\% using sterilization. In countries from sub-Saharan Africa, mCPR is $26.5 \%$ and overall LAPM use is low at less than $5 \%$, with less than $2 \%$ of women using implants and less than $2 \%$ using sterilization.

The positive relationship between wealth and LAPM use is an issue of concern as it may indicate that there is inequity in access to LAPMs in many developing countries. These differentials may be due to several reasons and have different remedies. Poor women may be less likely to use LAPMs due to financial barriers, which could be addressed by voucher programs that subsidize the costs of LAPM services. Similarly, contracting-out through NGOs could improve access to these methods so that women do not have to pay full price through private providers and facilities. Geographic barriers may be an issue for poor women, which is more difficult to address. This may require more concerted efforts to provide LAPMs through highquality, mobile outreach services in poor areas. ${ }^{28} \mathrm{In}$ addition, the expansion of social franchising programs can remove geographic barriers by training providers in hard-to-reach areas in the provision of LAPMs, while ensuring they have needed supplies and quality standards. ${ }^{29,30}$ Lack of information among women and/or their spouses may lead couples to be less likely to use LAPMs. Addressing this issue would require a concerted effort by both the public and the private sectors, so that messages focus on the benefits of these methods rather than on the specific type of provider. For example, in Jordan, a private-sector health project funded by the United States Agency for International Development (USAID) supported a behavior change communication campaign that focused on the benefits of using IUDs. The project demonstrated changes in knowledge, attitudes, and intention to use IUDs without focusing on the source of the 
method (public versus private sector). ${ }^{31}$ Addressing the problem of lack of information about LAPMs also requires that community health workers who do not provide the methods be conversant in the benefits and referral systems so that women and couples can access the full range of methods that helps them achieve their reproductive goals. It also may be possible that poorer women simply have different preferences. Follow-up formative research and intervention testing is required to disentangle the reasons we find this strong association across a large number of countries.

\section{Limitations}

The analysis has several limitations. First, the DHS data do not provide specifics such as location and proximity to services, which influence access to methods. These characteristics may be correlated with both household wealth and contraceptive choice. Second, for the purposes of this analysis we have grouped all types of LAPMs together due to the issue of sample size; however, we might find differing patterns for long-acting reversible methods (IUDs and implants) versus permanent methods (male and female sterilization). Third, in a few countries, the use of any modern method was low across all wealth quintiles, but especially in the lowest wealth quintiles; in those countries (Nigeria is a good example), we found no statistical significance across the key wealth coefficients, but that may be due to small sample size of women from those quintiles using modern methods. Fourth, this analysis provides a snapshot of current behavior; it does not capture change over time. Despite its limitations, this paper demonstrates a strong, positive relationship between wealth and LAPM use in many developing countries that deserves further exploration.

\section{CONCLUSION}

In most developing countries, wealthier women are more likely than poorer women to use longacting and permanent methods of contraception than short-acting methods. Notable exceptions are Bangladesh, India, and possibly Haiti, where poorer women are more likely to use long-acting and permanent methods than wealthier women, perhaps reflecting a different policy environment than in other countries.

Acknowledgments: The authors are grateful for comments and suggestions by Susan Mitchell, Marianne El-Khoury, Caroline Quijada, and Ayman Mohsen. They also appreciate the thoughtful comments provided by technical and quality reviewers, Slavea Chankova and
Francis Okello, and acknowledge early contributions to this study from Thierry van Bastelaer, Aisha Talib, and Quoc Long. The authors acknowledge financial support from the United States Agency for International Development Office of Population and Reproductive Health (Cooperative Agreement GPO-A-00-09-00007-00) via the Strengthening Health Outcomes through the Private Sector (SHOPS) Project.

Competing Interests: None declared.

\section{REFERENCES}

1. Family Planning 2020 (FP2020). FP2020 commitment to action 2014-2015. New York: FP2020; 2015. Available from: http://progress.familyplanning2020.org/uploads/15/02/ 2_FP2020_Commitment_to_Action_2014__2015_ printer_friendly.pdf.

2. Wickstrom J, Jacobstein R. Contraceptive security: incomplete without long-acting and permanent methods of family planning Stud Fam Plann. 2011;42(4):291-298. CrossRef. Medline

3. Tumlinson K, Steiner MJ, Rademacher KH, Olawo A, Solomon M, Bratt J. The promise of affordable implants: is cost recovery possible in Kenya? Contraception. 2011;83(1):88-93. CrossRef. Medline

4. Ross J, Weissman E, Stover J. Contraceptive projections and the donor gap: meeting the challenge. Brussels: Reproductive Health Supplies Coalition; 2009. Available from: http://www. rhsupplies.org/uploads/tx_rhscpublications/RHSCFundingGap-Final.pdf

5. Ugaz JI, Chatterii M, Gribble JN, Mitchell S. Regional trends in the use of short-acting and long-acting contraception accessed through the private and public sectors. Int J Gynecol Obstet. 2015;130 Suppl (3):E3-E7. CrossRef. Medline

6. Gakidou $E$, Vayena $E$. Use of modern contraception by the poor is falling behind. PLoS Med. 2007;4(2):e31. CrossRef. Medline

7. Creanga AA, Gillespie D, Karklins S, Tsui AO. Low use of contraception among poor women in Africa: an equity issue. Bull World Health Organ. 2011;89(4):258-266. CrossRef. Medline

8. de Oliveira IT, Dias JG. Disentangling the relation between wealth and contraceptive use in India: a multilevel probit regression approach. Qual Quant. 2014;48(2):1001-1012. CrossRef.

9. Ahmed S, Creanga A, Gillespie D, Tsui AO. Economic status, education and empowerment: implications for maternal health service utilization in developing countries. PLoS One. 2010;5(6): el1190. CrossRef. Medline

10. Ross JA, Agwanda AT. Increased use of injectable contraception in sub-Saharan Africa. Afr J Reprod Health. 2012;16(4):68-80. Medline

11. Fotso J, Speizer IS, Mukiira C, Kizito P, Lumumba V. Closing the poor-rich gap in contraceptive use in urban Kenya: are family planning programs increasingly reaching the urban poor? Int J Equity Health. 2013;12(1):71. CrossRef. Medline

12. Mbizvo MT, Phillips SJ. Family planning: choices and challenges for developing countries. Best Pract Res Clin Obstet Gynaecol. 2014;28(6):931-943. CrossRef. Medline

13. Emmart $P$. Policy barriers to long-acting and permanent method use in Ghana. Washington (DC): Futures Group, Health Policy Initiative, Task Order I; 2010. Available from: http://www. healthpolicyinitiative.com/Publications/Documents/ 1365_1_Ghana_LAPM_Report_Final_FINAL_acc.pdf

14. Campbell M, Sahin-Hodoglugil NN, Potts M. Barriers to fertility regulation: a review of the literature. Stud Fam Plann. 2006;37 (2):87-98. CrossRef. Medline

15. Ross J, Hardee K, Mumford E, Eid S. Contraceptive method choice in developing countries. Int Fam Plan Perspect. 2002;28(1):32-40. CrossRef. 
16. Wang W, Wang S, Pullum T, Ametepi P. How family planning supply and the service environment affect contraceptive use: findings from four East African countries. DHS Analytical Studies No. 26. Calverton (MD): ICF International; 2012. Available from: http://dhsprogram.com/pubs/pdf/AS26/AS26.pdf

17. Rutstein SO, Johnson K. The DHS wealth index. DHS Comparative Reports No. 6. Calverton (MD): ORC Macro; 2004. Available from: http://dhsprogram.com/pubs/pdf/CR6/CR6.pdf

18. Howe LD, Hargreaves JR, Gabrysch S, Huttly SRA. Is the wealth index a proxy for consumption expenditure? A systematic review. J Epidemiol Community Health. 2009;63(11):871-877. CrossRef. Medline

19. Montgomery MR, Gragnolati M, Burke KA, Paredes E. Measuring living standards with proxy variables. Demography. 2000;37(2):155-174. CrossRef. Medline

20. Potter F, Jang D, Friedman E, Diaz-Tena N, Ghosh B. Comparison of procedures to account for certainty primary sampling units. In: Joint Statistical Meetings (JSM) Proceedings, Survey Research Methods Section. Alexandria (VA): American Statistical Association; 2003. p. 3360-3365. Available from: http://www.amstat.org/sections/ srms/proceedings/y2003/files/jsm2003-000888.pdf

21. MEASURE Evaluation. The future of long-acting and permanent methods of contraception in Bangladesh: a policy brief. Chapel Hill (NC): MEASURE Evaluation; 2014. Available from: http:// www.cpc.unc.edu/measure/resources/publications/fs-14-131

22. International Institute for Population Sciences (IIPS); Macro International. National family health survey (NFHS-3), 2005-06: India: volume I. Mumbai: IIPS; 2007. Available from: https:// dhsprogram.com/pubs/pdf/FRIND3/FRIND3-Vol1AndVol2.pdf

23. de Oliveira IT, Dias JG, Padmadas SS. Dominance of sterilization and alternative choices of contraception in India: an appraisal of the socioeconomic impact. PLoS One. 2014;9(1):e86654. CrossRef. Medline

24. Sullivan TM, Bertrand JT, Rice J, Shelton JD. Skewed contraceptive method mix: why it happens, why it matters. J Biosoc Sci. 2006;38(04):501-521. CrossRef. Medline

25. Das $A$, Contractor $S$. India's latest sterilisation camp massacre. BMJ. 2014;349:g7282. CrossRef. Medline

26. Donaldson PJ. The elimination of contraceptive acceptor targets and the evolution of population policy in India. Popul Stud (Camb). 2002;56(1):97-110. CrossRef. Medline

27. Strengthening Health Outcomes through the Private Sector (SHOPS) project. Contraceptive prevalence by method and source (public and private). Bethesda (MD): Abt Associates, SHOPS project; 2012. Available from: https://data.shopsproject.org/ method.html

28. Duvall S, Thurston S, Weinberger M, Nuccio O, Fuchs-Montgomery $\mathrm{N}$. Scaling up delivery of contraceptive implants in sub-Saharan Africa: operational experiences of Marie Stopes International. Glob Health Sci Pract. 2014;2(1):72-92. CrossRef. Medline

29. Munroe E, Hayes B, Taft J. Private-sector social franchising to accelerate family planning access, choice, and quality: results from Marie Stopes International. Glob Health Sci Pract. 2015; 3(2):195-208. CrossRef. Medline

30. Thurston S, Chakraborty NM, Hayes B, Mackay A, Moon P. Establishing and scaling-up clinical social franchise networks: lessons learned from Marie Stopes International and Population Services International. Glob Health Sci Pract. 2015;3(2):180194. CrossRef. Medline

31. Khayame H. IUD social marketing campaign in Jordan. SHOPS Jordan; 2014. Available from: http://www.shopsproject.org/ resource-center/iud-social-marketing-campaign-in-jordan

\section{Peer Reviewed}

Received: 2015 Aug 4; Accepted: 2015 Dec 23; First Published Online: 2016 Feb 17

Cite this article as: Ugaz J, Chatterii M, Gribble JN, Banke K. Is household wealth associated with use of long-acting reversible and permanent methods of contraception? A multi-country analysis. Glob Health Sci Pract. 2016;4(1):43-54. http://dx.doi.org/10.9745/GHSP-D-15-00234.

(c) Ugaz et al. This is an open-access article distributed under the terms of the Creative Commons Attribution License, which permits unrestricted use, distribution, and reproduction in any medium, provided the original author and source are properly cited. To view a copy of the license, visit http:// creativecommons.org/licenses/by/3.0/. When linking to this article, please use the following permanent link: http://dx.doi.org/10.9745/GHSP-D-1500234. 